\title{
Immunoglobulin producing cells in bone marrow and blood of patients with multiple sclerosis and controls
}

\author{
Sten Fredrikson, Shahid Baig, Hans Link
}

\begin{abstract}
Multiple sclerosis (MS) is characterised by intrathecal synthesis of IgG, less frequently of IgA and IgM. Local production of antibodies to myelin basic protein (MBP) and other myelin components has also been reported, and autoimmune pathogenesis has been postulated. Whether MS is accompanied by a systemic B cell response is less clear. To elucidate this question, we examined bone marrow and peripheral blood from patients with MS and controls for cells secreting IgG, IgA and IgM, as well as anti-MBP antibodies of these three isotypes. Patients with MS without any signs of concurrent infections had higher numbers of IgG + IgA + IgM secreting cells both in bone marrow and peripheral blood compared with healthy controls. The same abnormalities were observed in patients with other inflammatory neurological diseases (OIND). When analysing individual isotypes, patients with MS and OIND had higher numbers of IgA secreting cells both in bone marrow and blood compared with healthy controls. Only one of $13 \mathrm{MS}$ patients examined had anti-MBP antibody secreting cells in bone marrow and blood. The systemic $B$ cell response registered in MS is also present in other inflammatory neurological diseases and its specificity and possible role in the pathogenesis of MS remains unknown.
\end{abstract}

Multiple sclerosis (MS) is an inflammatory disease affecting the central nervous system (CNS). The aetiology and pathogenesis have remained unknown although several immune aberrations have been reported in the cerebrospinal fluid (CSF) and to a certain extent also in peripheral blood. ${ }^{1}$ Evidence for a B cell response within the CNS-CSF compartment is the most consistent abnormality. It is demonstrable as elevated IgG index in about $75 \%$ of the MS patients and presence of oligoclonal IgG bands in practically all MS patients on separation of CSF proteins by isoelectric focusing or electrophoresis. ${ }^{2}$ Some indications of a systemic B cell response have also been reported, including the presence of oligoclonal IgG bands in serum from about $70 \%$ of MS patients when examined by sensitive isoelectric focusing and antiserum immunofixation, ${ }^{3}$ and elevated numbers of immunoglobulin secreting cells in peripheral blood. ${ }^{4}$ The specificity of synthesised immunoglobulins remains unknown, as has their possible role in the pathogenesis.

Bone marrow is the major source of B cells ${ }^{5}$ and also the major site of immunoglobulin production. ${ }^{6}$ In autoimmune diseases like systemic lupus erythematosus (SLE), increased immunoglobulin production in bone marrow has been described. ${ }^{7}$ In MS, however, no studies regarding the $B$ cell response in bone marrow have to our knowledge been reported. Nor has the immune function of bone marrow in MS been previously studied, until recently when we reported signs of mononuclear cell activation reflected by elevated spontaneous proliferation of MS bone marrow cells. ${ }^{8}$

The aim of this study was to evaluate the B cell response in bone marrow as reflected by numbers of IgG, IgA and IgM producing cells and to examine the response to myelin basic protein (MBP)—a putative autoantigen in MS-of bone marrow B cells in MS.

\section{Materials and methods}

PATIENTS AND CONTROLS

Bone marrow and peripheral blood cells were obtained from 13 patients (10 females) with clinically definite MS. Their age range was 25-67 years (mean 41). The duration of MS was 1-28 years (mean 8). Seven of the patients were examined during exacerbation, that is, there had been appearance of new signs and symptoms, or sudden reappearance or worsening of previous symptoms lasting more than 24 hours within four weeks before examination. None of the patients had ever been treated by immunomodulatory drugs including corticosteroids. None of these MS patients had any detectable concurrent infections.

Bone marrow and blood cells were also obtained from 10 patients (six females) with other inflammatory neurological diseases (OIND): neuroborreliosis (two patients), chronic inflammatory polyneuropathy (two), chronic meningitis (one), varicella zoster myelitis (one), encephalitis (one), neurosyphilis (one), chorioretinitis (one) and acute aseptic meningitis (one). Their age ranged between 24-76 years (mean 57). The healthy group for bone marrow B cell evaluation comprised seven individuals (five females), aged 27-61 years (mean 35). Six of these healthy individuals were medical students, and one was having elective orthopaedic surgery. None of them showed any signs of concurrent infections or other diseases.

Bone marrow aspirations were performed 
on patients after permission from the ethical committee and all samples were obtained with the patients' informed consent.

Bone marrow was aspirated from the iliac crest in heparinised glass tubes and mononuclear cells were isolated by density gradient centrifugation on Ficoll-Hypaque (Lymphoprep, Nyegaard, Oslo) and washed three times in phosphate buffered saline, $\mathrm{pH} 7 \cdot 4$ (PBS), diluted in Iscove's modification of Dulbecco's medium (Flow Laboratory, Irvine, UK) with 2 mmol 1-glutamine (Flow), antibiotics and $5 \%(v / v)$ fetal calf serum (Gibco, Paisley, $\mathrm{UK}$ ), and adjusted to $10^{6}$ cells per ml. Peripheral blood was obtained simultaneously as bone marrow aspirates, and mononuclear cells (PBL) were isolated in the same way.

Bovine MBP was prepared as described. ${ }^{9}$ The purity was checked by standard SDS polyacrylamide gel electrophoresis which showed a single band at about 21 kilodaltons.

A solid-phase enzyme-linked immunospot assay $^{1011}$ employing microtitre plates with 96 wells and nitrocellulose bottoms ${ }^{12}$ (Millititre HA, Millipore, USA) was used. To enumerate numbers of cells secreting IgG, IgA and IgM, wells were coated with high affinity-purified goat anti-human heavy chain specific IgG, IgA and IgM antiserum (Sigma, USA) in optimal dilution in PBS. For enumeration of cells secreting anti-MBP antibodies, the wells were coated with $100 \mu \mathrm{l}$ per well of MBP diluted in PBS to $10 \mu \mathrm{g} / \mathrm{ml}$. The plates were kept overnight at $4^{\circ} \mathrm{C}$. Coating solution was then removed by suction through the nitrocellulose membranes. The wells were then washed with PBS and $100 \mu$ l portions containing $10^{5}$ bone marrow cells or PBL were added into appropriate wells. After incubation overnight at $37^{\circ} \mathrm{C}$ in $7 \% \mathrm{CO}_{2}$ and humidified

Figure Numbers of IgG,
IgA and IgM secreting
cells per $10^{4}$ monomuclear
cells isolated from bone
marrow (upper panel) and
peripheral blood (lower
panel) from patients with
multiple sclerosis (MS),
other inflammatory
neurological diseases
(OIND) and healthy
controls (HC). Arrows
indicate mean values.

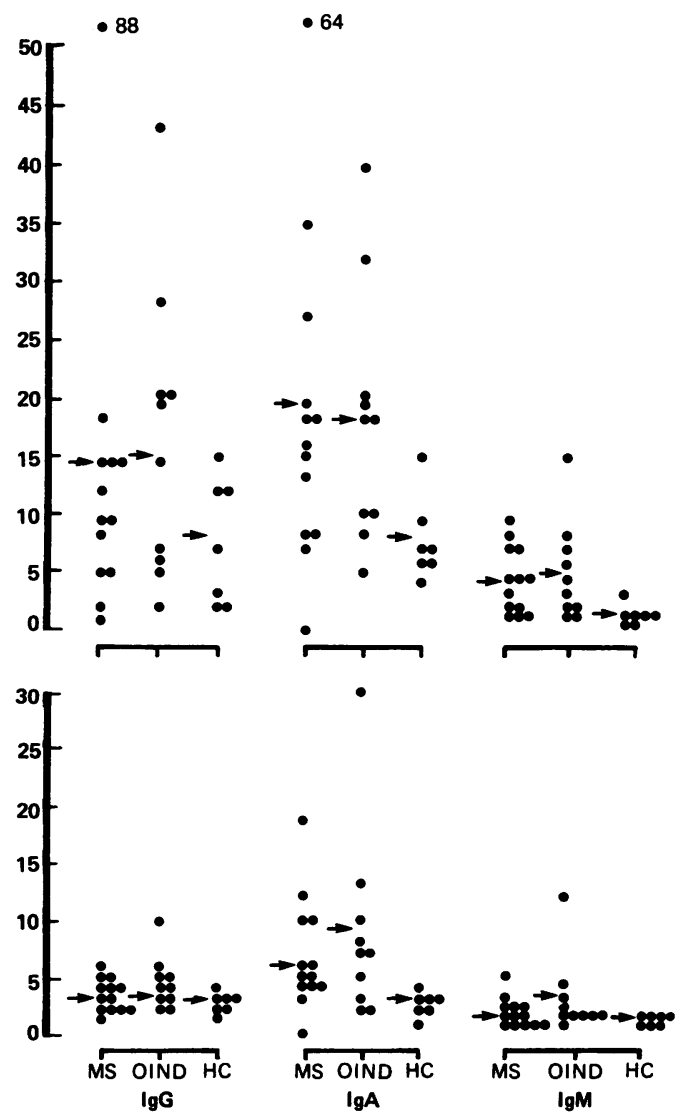

atmosphere, the wells were emptied and washed with PBS. One hundred microlitres of diluted high-affinity purified biotinylated goat anti-human IgG, -IgA and IgM antiserum (Sigma) was added to appropriate wells. After $3 \mathrm{~h}$ incubation with antiserum, the wells were washed with PBS and incubated for one hour with diluted avidin-biotin peroxidase complex (ABC Vectastain Kit, Vector Laboratories, USA), washed and stained with 3-amino-9ethylcarbazole (Sigma), dimethylformamide and $\mathrm{H}_{2} \mathrm{O}_{2}$ as substrate, then washed and dried. Immunospots formed were counted without knowledge of the diagnosis under a dissection microscope at a magnification of $\times 25$. Values obtained were standardised to numbers of spots per $10^{4}$ cultured cells. We have previously presented clear evidence that the spots which we detect in this system represent secretion of antibodies. ${ }^{13}$ Kruskal-Wallis test was used to compare the three groups simultaneously regarding differences in numbers of antibody secreting cells. Furthermore, to test the hypotheses that the levels of antibody secreting cells would differ between MS and HC, between MS and OIND, and between OIND and HC Mann-Whitney's U-test was used in each case. The probability values given in the text are two-tailed.

\section{Results}

Numbers of IgG, IgA and IgM secreting cells in bone marrow and peripheral blood per $10^{4}$ mononuclear cells and according to isotype distribution are shown in the figure, and numbers of cells secreting IgG + IgA + IgM are summarised in the table.

The numbers of IgG + IgA + IgM secreting cells in the bone marrow as well as in blood were higher in MS compared with healthy individuals $(p<0.05)$. A similar increase of IgG $+\operatorname{IgA}+\operatorname{IgM}$ secreting cells was found in the group of patients with OIND compared with the healthy controls ( $p$ $<0.05$ ) (table). When considering individual immunoglobulin isotypes, higher numbers of Ig A secreting cells were found both in bone marrow and peripheral blood of MS patients ( $\mathrm{p}<0.05$ and $\mathrm{p}<0.02$, respectively), but also in OIND ( $p<0.05$ ), compared with healthy controls. IgG and IgM secreting cells were also present in higher numbers in bone marrow in both MS and OIND compared with healthy individuals, but the differences did not reach statistical significance. There were no differences between MS and OIND of immunoglobulin producing cells either in

Table Numbers of cells secreting IgG $+\operatorname{Ig} A+\operatorname{Ig} M$ in multiple sclerosis (MS), other inflammatory neurological diseases (OIND), and healthy controls (HC). Values are given per $10^{4}$ mono-nuclear cells

\begin{tabular}{lllc}
\hline & & \multicolumn{2}{c}{$\operatorname{IgG}+\operatorname{IgA}+\operatorname{Ig} M$} \\
\cline { 3 - 4 } Diagnosis & & $B M$ & $P B$ \\
\hline MS & Range & $6-161$ & $5-26$ \\
$\mathrm{n}=13$ & Mean (SD] & $39(27)$ & $12(6)$ \\
& Median & 27 & 11 \\
OIND & Range & $14-69$ & $5-38$ \\
$\mathrm{n}=10$ & Mean (SD) & $39(20)$ & $16(10)$ \\
& Median & 30 & 14 \\
$\mathrm{HC}$ & Range & $8-34$ & $4-9$ \\
$\mathrm{n}=7$ & Mean (SD) & $17(9)$ & $6(2)$ \\
& Median & 20 & 7 \\
\hline
\end{tabular}


the bone marrow or in the peripheral blood.

In all groups, numbers of immunoglobulin secreting cells were higher in bone marrow compared with peripheral blood ( $p<0.001)$.

We detected no correlation between numbers of immunoglobulin producing cells and disability or duration of disease in the patients with MS.

Anti-MBP B cell response was evaluated in bone marrow and peripheral blood from all MS patients, from eight patients with OIND and seven healthy individuals. All groups were negative for anti-MBP IgG, IgA and IgM antibody producing cells with the exception of one MS patient who had two antiMBP IgG antibody secreting cells per $10^{4}$ mononuclear cells.

\section{Discussion}

Studies on immunoglobulin production in bone marrow of MS patients have not been reported earlier, despite the fact that elevated immunoglobulin production within the CNSCSF compartment is the most consistent laboratory finding in MS. This study shows elevated numbers of IgG $+\operatorname{IgA}+\operatorname{IgM}$ producing cells in MS bone marrow compared with healthy controls. This increase in bone marrow is not specific for MS since we found similar changes in a group of patients with OIND. It should be emphasised that none of the MS patients had any signs of concurrent infections.

Bone marrow has been reported to be the major source of all classes of immunoglobulins in serum. ${ }^{6}$ It has been proposed that antibody formation is regulated in such a way that peripheral lymphoid tissues respond rapidly, while bone marrow starts slowly but instead gives rise to long-lasting massive production of antibodies to antigens which repeatedly challenge the organism. ${ }^{14}$ Whether the antibody formation in bone marrow is dependent on antigen activated $B$ cells recruited from elsewhere or depends on local induction of antibody formation has been discussed, since bone marrow has been considered to lack appropriate microenvironment and possibly also feedback suppressor mechanisms, thereby explaining the long-lasting response. ${ }^{14} \mathrm{~A}$ role for bone marrow in autoimmune diseases has been shown, for example, in autoimmune thrombocytopenic purpura where bone marrow was found to be the major source of autoantibody production, ${ }^{15}$ and in rheumatoid arthritis where plaque-forming cells producing rheumatoid factor were more numerous in bone marrow than in other lymphoid organs. ${ }^{16}$ In this study we could not detect any anti-MBP antibody producing cells in bone marrow or peripheral blood except in one MS patient. This is of interest since recent studies have described frequent occurrence in MS CSF of cells secreting antibodies to $\mathrm{MBP}^{17}$ and of anticollagen antibody secreting cells in synovial fluid in rheumatoid arthritis. ${ }^{18}$ In both these situations, the autoantibody response is compartmentalised to the target organ.

The predominance of IgA response in bone marrow found in this study of patients with MS compared with healthy controls, was not specific for MS but also present in patients with other inflammatory neurological diseases. Elevated numbers of IgA producing cells in the blood of MS patients have been reported earlier. ${ }^{4}$ IgA production is mostly related to mucosal immunity and secretory tissues contain predominantly IgA producing cells. In humans, IgA is synthesised within the bone marrow, and serum concentrations of $\operatorname{IgA}$ are correlated to its bone marrow production. ${ }^{19}$ The direct relation between mucosal immune system and bone marrow immunoglobulin secreting cells has been shown. ${ }^{14}$ The mechanisms behind elevated IgA production in MS and OIND remain to be elucidated.

In conclusion, we have demonstrated that immunoglobulin secreting cells especially of the IgA isotype are increased in the bone marrow of patients with MS but also in other inflammatory diseases of the nervous system compared with healthy controls. The mechanisms behind this B cell activation detectable in bone marrow are unknown. Whether the reported aberrations in bone marrow of MS patients have any pathogenetic role remain unclear and warrant further studies of the systemic B cell response in patients with MS.

This study was supported by the Tore Nilson Foundation and the Swedish MS Foundation. We thank Ms Yvonne Nilsson for excellent secretarial help.

1 Reder AT, Arnason BGW. Immunology of multiple sclerosis. In: Koestler JL, et al, eds. Handbook of clinical neurology, vol 3 (47). Amsterdam: Elsevier, 1985:337-95.

2 Link H. Cerebrospinal fluid in immunological CNS diseases. In: Aarli JA, Behand WMH, Beha PO, eds. Oxford: Blackwell Scientific Publications, 1987:444-66.

3 Laurenzi MA, Mavra M, Kam-Hansen S, Link H. Oligoclonal IgG and free light chains in multiple sclerosis demonstrated by thin-layer polyacrylamide gel ioelectric focusing and immunofixation. Ann Neurol 1980;8:241-7.

4 Henriksson A, Kam-Hansen S, Link H. IgM, IgA and IgG producing cells in cerebrospinal fluid and peripheral blood producing cells in cerebrospinal fluid and peripheral blood

5 Abdou NI, Richter M. The role of bone marrow in immune response. Adv Immunol 1970;12:210-62.

6 McMillan R, Longmire RL, Yelenosky R, Lang JE, Heath $V$, Craddock CG. Immunoglobulin synthesis by human lymphoid tissues: normal bone marrow as a major site of IgG production. J Immunol 1972;109:1386-94.

7 Fauci AS, Moutsopoulos HM. Polyclonally triggered B cells in peripheral blood and bone marrow of normal individuals and in patients with systemic lupus erythematosus and primary Sjögren's syndrome. Arthr Rheum 1981;24:577-584.

8 Fredrikson S, Kam-Hansen S, Lu CZ, Eriksson LC. Bone marrow cells in patients with multiple sclerosis. $J$ Neuroimmunol 1989;24:23-31.

9 Deibler GE, Martensson RE, Kies MW. Large scale preparation of myelin basic protein from central nervous preparation of myelin basic protein from central nervous 1972;2:139-65.

10 Czerkinsky CC, Nilsson LA, Nygren H, Ouchterlony Ö, Tarkowski A. A solid-phase enzyme-linked immunospot assay for enumeration of specific antibody secreting cells. $J$ Immunol Meth 1983;65:109-21.

1 Sedgewick JD, Holt PG. A solid-phase immunoenzymatic technique for the enumeration of specific antibody secreting cells. J Immunol Meth 1983;57:301-9.

2 Möller SA, Borrebaeck CAR. A filter immunoplaque assay for detection of antibody-secreting cells in vitro. Immunol Meth 1985;79:195-204.

13 Zachau A, Strigärd K, Baig S, Höjeberg B, Olsson T Distribution of plasma cells secreting antibodies against nervous tissue antigens during experimental allergic encephalomyelitis enumerated by nitrocellulose immunospot phsay. J Neurol Sci 1989;91:323-6.

14 Benner R, Hijmans W, Haaijman JJ. The bone marrow: The major source of serum immunoglobulins, but still a major source of serum immunoglobulins, but still a 1981;46:1-8.

15 McMillan R, Yelenosky RJ, Longmire RL. Antiplatelet antibody production by the spleen and bone marrow in immune thrombocytopenic purpura. In: Battist $\mathrm{JR}$, Streilein JW, eds. Immuno-aspects of the spleen. Amsterdam: Elsevier, 1976:227-34

16 Vaughan JH, Chikara TM, Moore TL, et al. Rheumatoid factor-producing cells detected by direct hemolytic plaque assay. J Clin Invest 1976;58:933-41.

17 Link H, Baig S, Jiang YP, et al. B cells and antibodies in MS. Ann Inst Pasteur/Immunol 1989;140:219-26.

18 Tarkowski A, Klareskog L, Carlsten H, Herberts P, Koopman WJ. Secretion of antibodies to type I and II collage by synovial tissue cells in patients with rheumatoid arthritis. Arthr Rheum 1989;32:1087-92.

19 Kutteh WH, Prince SJ, Mestecky J. Tissue origins of human polymetic and monomeric IgA. J Immunol 1982; 126:990-5. 